\title{
The Arabidopsis thaliana gametophytic mutation gemini pollen1 disrupts microspore polarity, division asymmetry and pollen cell fate
}

\author{
Soon Ki Park, Ross Howden and David Twell* \\ Department of Biology, University of Leicester, University Road, Leicester LE1 7RH, UK \\ *Author for correspondence (e-mail: twe@le.ac.uk) \\ Accepted 21 July; published on WWW 7 September 1998
}

\section{SUMMARY}

Pollen development and male gametogenesis are critically dependent upon cell polarization leading to a highly asymmetric cell division termed pollen mitosis I. A mutational approach was adopted in Arabidopsis thaliana to identify genes involved these processes. Four independent gemini pollen mutants were isolated which produce divided or twin-celled pollen. The gemini pollen1 mutant was characterized in detail and shown to act gametophytically resulting in reduced transmission through both sexes. gemini pollen1 showed an incompletely penetrant phenotype resulting in equal, unequal and partial divisions at pollen mitosis I. The division planes in gemini pollen1 were shown to be aligned with the polar axis (as in wild type) and evidence was obtained for incomplete nuclear migration, which could account for altered division symmetry. gemini pollen1 also showed division phenotypes consistent with spatial uncoupling of karyokinesis and cytokinesis suggesting that GEMINI POLLEN1 may be required for the localization of phragmoplast activity. Cell fate studies showed that in both equal and unequal divisions a vegetative cell marker gene was activated in both daughter cells. Daughter cells with a range of intermediate or hybrid vegetative/ generative cell fates suggests that cell fate is quantitatively related to cell size. The potential mode of action of GEMINI POLLEN1 and its effects on cell fate are discussed in relation to proposed models of microspore polarity and cell fate determination.

Key words: gemini pollen, Arabidopsis thaliana, cell polarity, asymmetric cell division, cell fate, cytokinesis, lat52, quartet, tetrad analysis

\section{INTRODUCTION}

A key event in the differentiation of the angiosperm male gametophyte is the highly asymmetric division of the haploid microspore termed pollen mitosis I (PMI). This division produces two unequal daughter cells, the vegetative and generative cells, that have dramatically different structures and developmental fates (reviewed by Tanaka, 1997 and Twell et al., 1998). The large vegetative cell (VC) accumulates an abundance of stored metabolites required for rapid pollen tube extension, while the diminutive generative cell (GC) is enclosed by the VC cytoplasm and contains relatively few organelles and stored metabolites. This extreme dimorphism is also reflected in cell cycle progression and the expression of specific genes (reviewed by Twell, 1994). These characteristics provide differential cell fate markers since the $\mathrm{VC}$ exits the cell cycle and activates the pollen-specific lat52 promoter, while the GC completes a further division to form the two sperm cells and fails to activate lat52 (Twell, 1992; Eady et al., 1994, 1995). Although identified GC-specific proteins (Ueda and Tanaka, 1995) have not yet been developed as cell fate markers, repressed lat52 expression, continued division and condensed nuclear chromatin provide markers of GC fate.

The importance of division asymmetry at PMI in controlling differential cell fate has long been recognised (reviewed by La Cour, 1949). Early observations showed that the differentiation of vegetative and generative cells was clearly associated with a qualitative difference in the cytoplasm surrounding the nuclei following asymmetric division at PMI (La Cour, 1949). Observations of induced or spontaneously occurring aberrant divisions at PMI showed that altered division asymmetry could lead to incomplete differentiation and altered cell fate (La Cour, 1949). Further studies of nuclear and cytoplasmic differentiation in aberrant divisions induced by colchicine or temperature stress, confirmed the importance of division asymmetry for GC differentiation (reviewed by Tanaka 1997; Twell and Howden, 1998). More recently a molecular marker has been used to monitor vegetative cell fate in colchicine-induced aberrant divisions at PMI in tobacco. In induced symmetrical divisions the nuclear localized VC fate marker gene lat52gus/nia was activated in both equal daughter cells (Eady et al., 1995). Furthermore, when division at PMI was blocked, uninucleate 'pollen grains' also expressed VC fate. These results confirm that division asymmetry at $\mathrm{PMI}$ is essential for $\mathrm{GC}$ differentiation, involving the repression of $\mathrm{VC}$ specific genes and chromatin condensation, and further demonstrate that VC-specific gene activation can be uncoupled from cell division. These studies led to the 
proposal of a default gametophytic (vegetative) cell fate controlled by gametophytic transcription factors that reach threshold activity at PMI by a pathway independent of cytokinesis (Eady et al., 1995). The polarized distribution and differential inheritance of such positive and/or negative factors could account for differential cell fate as a result of asymmetric division at PMI (Eady et al., 1995; Twell et al., 1998).

Given the critical role of asymmetric division in the control of pollen cell fate, how does the microspore develop the necessary polarity to achieve asymmetric division? Pharmacological and immunolocalization studies strongly implicate the cytoskeleton in polar nuclear migration and spindle axis determination (reviewed by Twell and Howden 1998). For example, a specialised generative pole microtubule system appears at the future GC pole prior to nuclear migration in the orchid Phalaenopsis (Brown and Lemmon, 1991, 1992). Both microtubules and actin microfilaments have been implicated in the maintenance of the acentric position of the microspore nucleus (Tanaka and Ito, 1981; Terasaka and Niitsu, 1990; Gervais et al., 1994) and single microtubules have been observed 'tethering' the nucleus to the plasma membrane (Hause et al., 1991; Brown and Lemmon, 1991, 1992). The development of the single large vacuole before division at pollen mitosis I has also been suggested to play a role in the repositioning the microspore nucleus (Terasaka and Niitsu, 1990). However this possibility can be excluded in orchids such as Phalaenopsis which possess non-vacuolate microspores (Brown and Lemmon, 1991).

The efficacy of a genetic approach in dissecting polarity and asymmetric division in other organisms (Horvitz and Herskowitz, 1992; Jan and Jan, 1998), suggests that this will also be a powerful approach for the dissection of microspore polarity and cell fate determination. In this regard it would be expected that gametophytically expressed genes would play an important role. A significant number of gametophytic mutations have been identified, which affect, for example, pollen size, metabolic enzyme activity or pollen tube growth (reviewed by Twell, 1994; Sari-Gorla, 1996). Recently, through the application of mutagenesis and gene tagging strategies in Arabidopsis thaliana, several distinct classes of gametophytic mutants have been isolated which affect the stereotypical pollen cell divisions.

limpet pollen prevents engulfment and inward migration of the generative cell (Howden et al., 1998). sidecar pollen (scp) undergoes a premature symmetric division of the microspore with only one daughter cell able to polarize and produce two sperm cells (Chen and McCormick, 1996). In solo pollen mutants, division at PMI is blocked resulting in uninucleate pollen, duo pollen mutants prevent division of the generative cell at PMII and gemini pollen ( $\mathrm{gem}$ ) mutants affect the symmetry of division at PMI (reviewed by Twell and Howden, 1998). In this paper we describe the isolation of four independent gem mutants. The gem 1 mutant was characterised in detail including the analysis of gametophytic transmission, division axis at PMI and daughter cell fate. The potential mode of action of GEMI and its effect on cell fate are discussed in relation to current and proposed models of microspore polarity and cell fate determination.

\section{MATERIALS AND METHODS}

\section{Mutant screen and growth conditions}

Plants were grown in 3:1 compost:sand mix, under greenhouse conditions with supplementary lighting ( 16 hours light, $\left.22^{\circ} \mathrm{C}\right)$. The parental seed used for mutagenesis was a homozygous transgenic line harbouring the lat52-gus gene fusion (Eady et al., 1994) in the Nossen (No-0) background. Seed was mutagenised with EMS by Lehle Seeds, and pollen from approximately $1000 \mathrm{M}_{2}$ individuals derived from each of ten $M_{1}$ parental groups screened for visible phenotypes. A single open flower from each $\mathrm{M}_{2}$ plant was immersed in DAPI staining solution in a microtitre plate and examined on an Zeiss Axiophot 135 microscope.

\section{Cytological and phenotypic analysis of pollen}

Detailed phenotypic characterization was carried out on a Nikon Optiphot microscope using light and epifluorescence microscopy. Images were captured directly using a 3-CCD colour video camera (JVC, KY-F55B), linked to a Neotech IGPCI capture card and ImageGrabber PCI 1.1 software on an Apple Macintosh computer. Image processing and analysis was performed with Adobe PhotoShop 4. For confocal laser scanning microscopy (CLSM) mature pollen was incubated in $1 \mu \mathrm{g} / \mathrm{ml}$ ethidium bromide (EtBr) and viewed using a Leica TCS4D CLSM with an excitation wavelength of $568 \mathrm{~nm}$ and emission filter at $630 \pm 30 \mathrm{~nm}$.

\section{DAPI staining}

Sufficient mature pollen was obtained by placing 3-4 open flowers in a microfuge tube containing $300 \mu \mathrm{l}$ of DAPI staining solution $(0.1 \mathrm{M}$ sodium phosphate (pH 7), 1 mM EDTA, $0.1 \%$ Triton X-100, $0.4 \mu \mathrm{g} / \mathrm{ml}$ DAPI; high grade, Sigma). After brief vortexing and centrifugation the pollen pellet was transferred to a microscope slide and viewed by light and by UV epi-illumination. For the analysis of spores at earlier stages, single anthers were dissected from isolated buds using a dissecting microscope (Zeiss, Stemi SV8). Anthers were disrupted on microscope slides using dissecting needles and gently squashed in DAPI staining solution $(1 \mu \mathrm{g} / \mathrm{ml})$ under a coverslip.

\section{Preparation of anther sections}

Thick sections of fixed anthers were prepared essentially according to the method of Owen and Makaroff (1995). Thick sections $(1 \mu \mathrm{m})$ were cut on a Reichert Jung Ultramicrotome using glass knives, mounted on glass slides and stained with $0.5 \%$ toluidine blue in $2 \%$ sodium borate.

\section{Vegetative cell fate analysis}

For the analysis of cell fate using the nuclear-targeted vegetative cellspecific lat52-gus/nia marker (Twell, 1992), the lat52-gus marker gene present in the parental genetic background (Twell et al., 1990) was first segregated away from geml by back crossing to No-0. geml mutant progeny which were GUS negative in pollen were crossed with a transgenic line homozygous for the lat52-gus/nia transgene in the No-O background (Eady et al., 1994). F $F_{1}$ progeny were identified which showed both nuclear-targeted GUS staining and the geml phenotype. To visualize GUS staining, pollen was incubated overnight at $37^{\circ} \mathrm{C}$ in GUS buffer ( $0.1 \mathrm{M}$ sodium phosphate ( $\left.\mathrm{pH} 7\right), 1 \mathrm{mM}$ EDTA, $0.1 \%$ Triton $\mathrm{X}-100,5 \mathrm{mM}$ potassium ferricyanide) containing $1 \mathrm{mM}$ 5-bromo-4-chloro-3-indolyl $\beta$-D-glucuronic acid (X-gluc; Biosynth).

\section{Genetic analysis and mapping}

Genetic transmission of geml through the male and female gametes was determined by carrying out reciprocal test crosses in which heterozygous gem mutants were crossed to wild type (No-0) and the pollen phenotype of the progeny scored. The transmission efficiency (TE) of the mutant allele through each gamete describes the fraction of mutant alleles that are successfully transmitted to the progeny (Howden et al., 1998). If the mutant allele is transmitted with $100 \%$ 
efficiency, test cross progeny should segregate 1:1 for mutant:wildtype plants (assuming equal numbers of both alleles and random segregation of alleles at meiosis). Therefore among test cross progeny the number of mutants/number of wild-type plants $\times 100$ represents the percentage of gametes carrying the mutant allele that successfully transmit the mutation (transmission efficiency).

Tetrad analysis was performed by isolating the +/gem1; qrt1/qrt1 double mutant. The homozygous qrtl mutant was crossed to a heterozygous $+/$ gem 1 mutant and $\mathrm{F}_{1}$ plants screened to identify those with the gemini phenotype (+/geml;QRT1/qrt1). +/geml;qrtl/qrt1 individuals in the $\mathrm{F}_{2}$ population were identified by screening for plants showing both quartet and gemini phenotypes.

The geml mutation was mapped using PCR based molecular markers. Plants heterozygous for geml were outcrossed to plants of wild-type Columbia (Col). $\mathrm{F}_{1}$ plants heterozygous for $\mathrm{gem} 1$, identified by screening DAPI-stained pollen, were allowed to self-fertilize. DNA was isolated from leaves of the gem $1 \times \mathrm{Col} \mathrm{F}_{2}$ population according to the method of Edwards et al. (1991) and used for PCR-based mapping using SSLP markers which show useful polymorphism between No-0 and Col (Bell and Ecker, 1994). Only the GEM1/GEM1 homozygote class was used in $\mathrm{F}_{2} / \mathrm{F}_{3}$ mapping since recombinant chromosomes carrying the geml mutation would show reduced transmission. geml was demonstrated to map on the lower arm of chromosome 2, $14.9 \pm 4.45 \mathrm{cM}$ and $10.1 \pm 1.54 \mathrm{cM}$ south of SSLP markers AthBIO2 and nga168 respectively, through the analysis of $F_{2}$ data using the Kosambi mapping function (Koornneef and Stam, 1992).

\section{RESULTS}

\section{Isolation of gemini pollen mutants}

Mutants that divide more symmetrically at PMI are expected to result from lesions in components required for polarity determination or expression and could act sporophytically and/or gametophytically. To identify such mutants, approximately $10,000 \quad \mathrm{M}_{2}$ individuals from an EMS mutagenised (ecotype No-0) population were screened by examining DAPI-stained pollen by light and epifluorescence microscopy. Four individuals termed gemini pollen (gem) mutants arising in different $\mathrm{M}_{1}$ parental groups were identified,
Table 1. Frequency of phenotypic classes in gemini pollen mutants

\begin{tabular}{lcccccr}
\hline \multirow{2}{*}{$\begin{array}{l}\text { Phenotypic } \\
\text { class }\end{array}$} & \multicolumn{5}{c}{ Percentage of spores in each phenotypic class } \\
\cline { 2 - 7 } & WT & gem ${ }^{*}$ & gem ${ }^{\dagger}$ & gem 2 & gem3 & gem4 \\
\hline Wt & 98.7 & 80 & 61.8 & 87.8 & 86.3 & 87.6 \\
solo & - & 6.8 & 14.2 & 3.7 & 1.5 & 1.4 \\
gemini & - & 8.3 & 16.3 & 1.1 & 1.7 & 1.7 \\
duo & 0.8 & 1.6 & 3.2 & 1.6 & 2.5 & 2.1 \\
trio & - & - & - & - & 4.9 & 4.1 \\
aborted & 0.5 & 3.3 & 4.5 & 5.8 & 3.1 & 3.1 \\
$\sum$ (aberrant) & 1.3 & 20.0 & 38.2 & 12.2 & 13.7 & 12.4
\end{tabular}

Counts were made on known heterozygous individuals except where indicated: $\mathrm{WT}=$ No-0 parental ecotype; $*$ gem 1 heterozygote; $\dagger$ gem 1 homozygote. Wt, wild type, trinucleate pollen; solo, uninucleate pollen; gemini = partially or completely divided pollen; duo, bicellular pollen; trio, smaller trinucleate pollen; aborted = collapsed pollen with no visible nuclei; $\sum$ (aberrant), sum total of all aberrant classes. Data are derived from $>1000$ spores counted from four backcross progeny.

which shed twin-celled pollen at anthesis. All four gem mutants showed several distinct aberrant phenotypes which were classified as solo pollen, duo pollen, trio pollen, gemini pollen and aborted pollen, at increased frequencies relative to the wild type (Table 1). Whereas wild-type plants showed only 1-2\% aberrant pollen, which was restricted to the aborted and duo pollen classes, the proportion of aberrant pollen in $+/ \mathrm{gem}$ heterozygotes varied from 12-20\% (Table 1). Although the distribution of pollen among the phenotypic classes varied significantly between the gem mutants all four produced solo, gemini, duo and aborted pollen. However smaller tricellular (trio) pollen was restricted to the gem 3 and gem 4 mutants. Since gem 1 showed the most severe division phenotypes, gem 1 was selected for detailed genetic and phenotypic characterization.

\section{gem1 disrupts cytokinesis and division asymmetry in developing pollen}

Mature geml pollen was stained with DAPI and examined by light and epifluorescence microscopy to determine pollen
Fig. 1. Morphology (light panels) and nuclear constitution (dark panels) of phenotypic classes in mature gem1 pollen. (A) Wild-type pollen with diffusely DAPI staining vegetative nucleus and two intensely staining sperm cell nuclei. (B) Solo pollen with a single nucleus staining more intensely than the vegetative nucleus of wild-type pollen. (C) Duo pollen with a vegetative and intensely staining generative nucleus $(\mathrm{D}, \mathrm{E})$ Solo pollen with partial (D) or complete (E) dividing wall. (F) Binucleate cell with unequal but more dispersed chromatin. (G) Same as F but partially divided. (H) Same as F but divided with enucleate partition. (I,J) Gemini pollen with equally (I) or unequally (J) divided pollen and equal or unequal staining nuclei. (K) Adjacent wild-type (tricellular) and larger solo pollen.
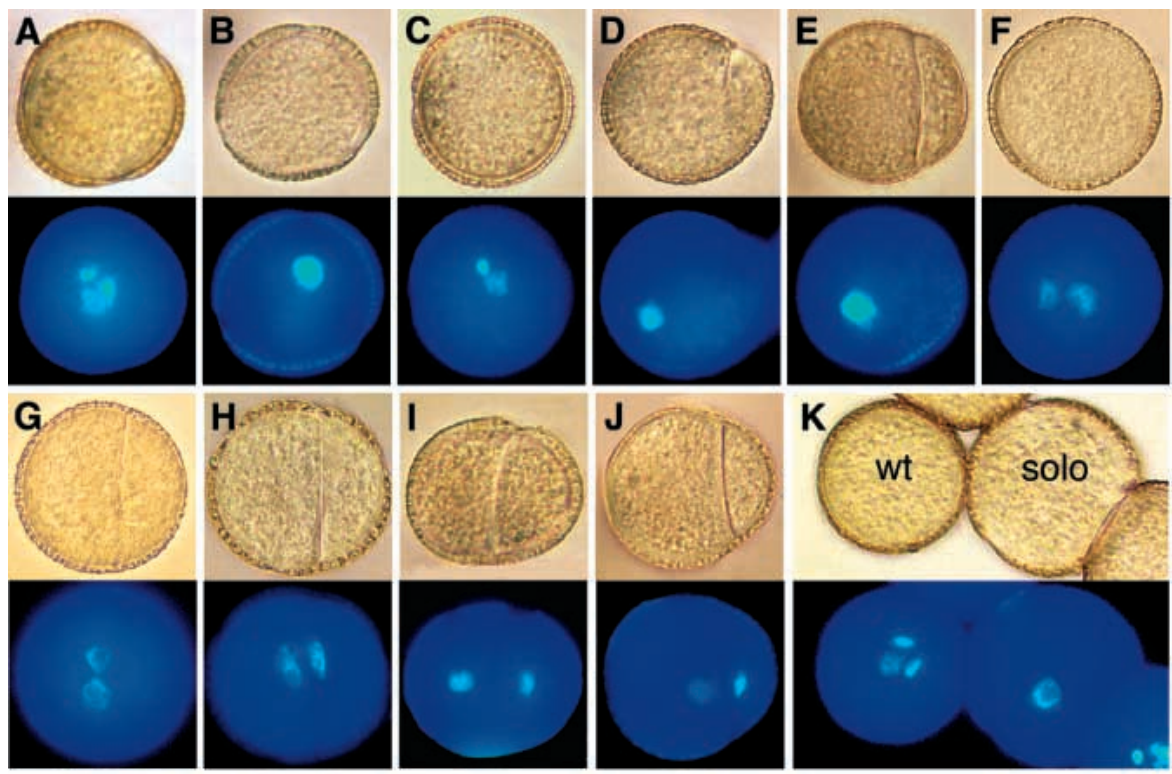


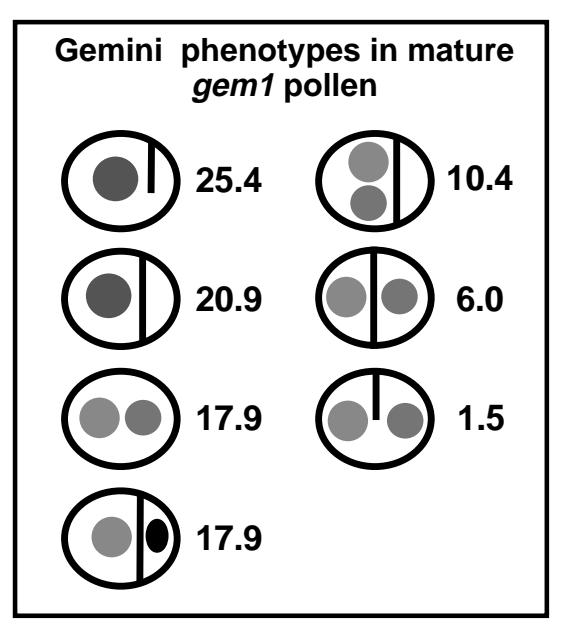

Fig. 2. Diagram illustrating the range and frequency of phenotypic subclasses within the gemini class present in mature gem 1 pollen. The frequency of each phenotypic subclass was calculated as a percentage of the total gemini class. The shading of pollen nuclei represents the observed intensity of fluorescence after DAPI staining which reflects chromatin condensation and/or DNA content.

morphology and nuclear phenotype (Fig. 1). The most frequent aberrant classes were solo and gemini pollen, which were present at a similar frequency $(\sim 14$ and $16 \%$ respectively) in homozygotes, representing $\sim 80 \%$ of the phenotypically aberrant pollen (Table 1 ). Solo pollen was larger in size than wild type and contained a single nucleus (Fig. 1B,K). Although solo pollen nuclei appeared dispersed and similar in size to the vegetative nucleus, nuclei stained more intensely with DAPI.

Pollen within the gemini class represented $\sim 43 \%$ of the phenotypically aberrant pollen (Table 1) and showed a range of division phenotypes which could be classified into seven distinct types including binucleate, equal, unequal and partial divisions (Fig. 1D-J). Binucleate cells with two differentially staining 'vegetative-like' nuclei (Fig. 1F), were present at a frequency of $\sim 18 \%$ of the gemini class (Fig. 2). Nearly equally divided cells with two differentially staining 'vegetative-like' nuclei (Fig. 1I) were observed at a frequency of $\sim 6 \%$ within the gemini class (Fig. 2), while clearly asymmetric divisions with differential nuclear staining (Fig. 1J) were observed at a frequency of $\sim 18 \%$ (Fig. 2). Therefore both cytokinesis and division asymmetry are frequently affected in geml.

One of the most common phenotypes, representing $~ 31 \%$ of the gemini class, was that asymmetric divisions often resulted in a smaller enucleate portion of the microspore cytoplasm being walled off from a larger cell containing either one (Fig. 1E) or two (Fig. 1H) nuclei with more dispersed chromatin (Fig. 2). A further $~ 27 \%$ showed incomplete divisions with one (Fig. 1D) or two (Fig. 1G) more diffusely staining nuclei present (Fig. 2). These mature pollen phenotypes show that geml can affect the positioning and efficiency of cell plate synthesis and suggest that GEMI is required for the coordination of karyokinesis and cytokinesis.

\section{Genetic characterization of gemini pollen mutants}

All four gem mutations were transmitted from the $\mathrm{M}_{2}$ through to the $\mathrm{M}_{5}$ generations and only a proportion of the test cross
A

\begin{tabular}{|l|c|c|c|c|c|}
\hline Transmission & Cross & $+/$ geml & $+/+$ & $\%$ gem1 & TE $(\%)$ \\
\hline Male & $+/+\mathrm{x}+/$ geml & 70 & 377 & 15.7 & 18.6 \\
\hline Female & $+/$ gem1 $\mathrm{x}+/+$ & 33 & 112 & 22.8 & 29.5 \\
\hline
\end{tabular}

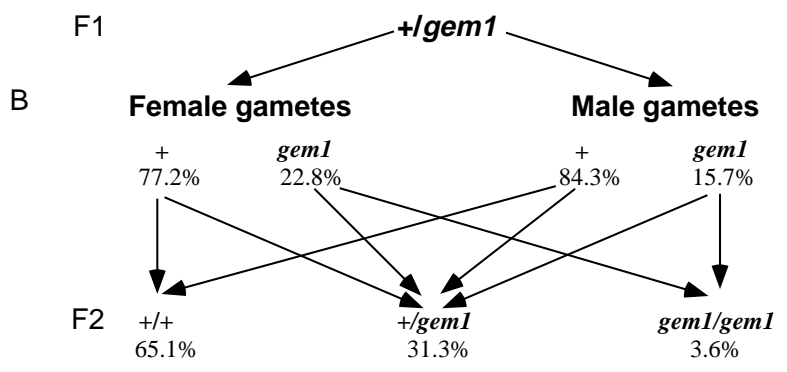

C

\begin{tabular}{|c|c|c|}
\hline $\begin{array}{c}\text { Self progeny of } \\
+/ g e m 1\end{array}$ & $+/$ gem $1+$ geml/gem 1 & $+/+$ \\
\hline Predicted & $34.9 \%$ & $65.1 \%$ \\
\hline Observed & $103(32.9 \%)$ & $210(67.1 \%)$ \\
\hline
\end{tabular}

Fig. 3. Genetic transmission of geml. (A) The number of geml $(+/$ gem 1$)$ and wild-type $(+/+)$ plants among test cross progeny and the percentage of gem 1 mutant progeny $(\% \mathrm{gem} 1)$. The transmission efficiency (TE) represents the percentage of gem 1 mutant alleles successfully transmitted through male or female gametes. (B) The predicted frequency of mutant geml and wild-type GEM1 (+) alleles in male and female gamete populations in $+/$ geml heterozygotes based on the observed frequency of geml and wild-type progeny in A. The reduced frequency of the gem 1 allele in male and female gamete populations was used to predict the frequencies of genotypic classes among self progeny of gem 1 heterozygotes shown in B. (C) The predicted and observed frequency of gem 1 mutants in self progeny of + /geml heterozygotes.

progeny showed the gemini pollen phenotype. Therefore, all of the gem mutations were originally isolated as heterozygotes and were predicted to act gametophytically or result from dominant sporophytic mutations. The proportion of mutants in $\mathrm{F}_{2}$ (self) progeny ranged from 30 to $58 \%$ (data not shown), less than the expected $75 \%$, further suggesting reduced gametophytic transmission for each mutation. The transmission efficiency (TE) of the mutant geml allele through the male and female gametophytes was determined by carrying out reciprocal test crosses and scoring progeny for the gem 1 phenotype (Fig. 3A). TE represents the fraction (\%) of mutant alleles that successfully transmit the mutation. Only $18.6 \%$ of pollen carrying geml $(\mathrm{TE}=18.6 \%)$ and $29.5 \%$ of megagametophytes carrying geml $(\mathrm{TE}=29.5 \%)$ successfully transmitted the mutation, demonstrating that geml acts gametophytically in both sexes (Fig. 3A).

Self progeny were screened to identify homozygous gem 1 mutants. One individual which gave rise to $100 \%$ gem 1 mutant progeny was identified by progeny testing of $59 \mathrm{gem} 1$ mutant siblings. Throughout vegetative and floral development homozygous geml mutant plants appeared indistinguishable from the wild type, but the frequency of aberrant pollen was increased. Pollen was similarly distributed among the same phenotypic classes as in +/geml heterozygotes, however, there was an approximate two-fold increase in the frequency of 
aberrant pollen in each class (Table 1), further supporting the gametophytic action of geml.

The low frequency of geml homozygotes observed among +/geml self progeny would be expected as a result of the strongly reduced transmission of geml. The structure of the effective gamete populations in $+/$ gem 1 heterozygotes can be predicted based on the observed frequency of geml plants in test cross progeny (Fig. 3A). Since only $15.7 \%$ of the pollen population and $22.8 \%$ of the available ovules successfully transmit geml (Fig. 3B), homozygotes would be expected to occur at the reduced frequency of $3.6 \%$ (15.7\% of the $22.8 \%$ viable geml ovules). Furthermore, geml mutants would be predicted to represent $34.9 \%$ of $+/$ geml self progeny (Fig. 3C) which is similar to the frequency observed (32.9\%; Fig. 3C).

The geml mutation was mapped using PCR-based SSLP markers in an $\mathrm{F}_{2}$ population following outcrossing with the polymorphic Col wild type (see Materials and Methods for details). The geml mutation was mapped to a position on chromosome 2, $10.1 \mathrm{cM}$ south of SSLP marker nga168.

\section{gem1 is incompletely penetrant in pollen}

In a heterozygous plant harbouring a fully penetrant male gametophytic lethal mutation a maximum of $50 \%$ of the pollen population should show the phenotype. However, heterozygous geml mutants showed only $\sim 20 \%$ aberrant pollen. Therefore the remaining $30 \%$ that carry geml show an apparently wild-type phenotype. This reduced penetrance was confirmed in geml homozygotes which produced $\sim 40 \%$ phenotypically aberrant pollen (Table 1). Based on the reduced transmission of geml through the male $(\mathrm{TE}=$ $18.6 \%$ ), in + /geml heterozygotes the fraction of pollen carrying the gem 1 allele which failed to successfully fertilize an ovule and set viable seed was calculated to be $\sim 80 \%$ (Fig. 3 ). If all failed pollen showed a visible phenotype, in homozygotes one would expect $80 \%$ aberrant and $20 \%$ wildtype pollen. In fact only $40 \%$ appeared aberrant (Table 1). Therefore in the geml homozygote $60 \%$ of the pollen carry the geml mutation but appear wild type and of these two thirds fail to transmit geml.

\section{Tetrad analysis of gem1}

The quartet (qrt) mutants, in which pollen grains remain in permanent tetrads, enables tetrad analysis in Arabidopsis (Preuss et al., 1994). Plants heterozygous for a gametophytic mutation in the qrt/qrt background will show the phenotype in a maximum of two members of the tetrad. Analyses of tetrad phenotypes in plants with the $+/+;$ qrtl/qrtl and $+/$ gem 1; qrt 1/qrt1 genotypes are presented in Table 2 . Whereas $>99 \%$ of tetrads from homozygous qrtl plants appeared wild type, in +/gem1;qrt1/qrtl approximately $80 \%$ of tetrads contained aberrant pollen, with $30 \%$ showing two aberrant spores, $50 \%$ one aberrant spore. These data and the absence of tetrads with more than two aberrant spores further confirms the incompletely penetrant gametophytic role of gem 1. Although the overall frequency of solo, duo and gemini pollen in +/gem 1; qrt1/qrt1 mutants (hybrid No-0/Ler background) was similar to that observed in the $+/$ geml; QRTI/QRT1 (No-0 background), the frequency of aborted pollen increased from $3.3 \%$ (Table 1) to $15.8 \%$ (Table 2). Therefore geml appears to show increased penetrance in the No-0/Ler background expressed as an increase in aborted pollen.

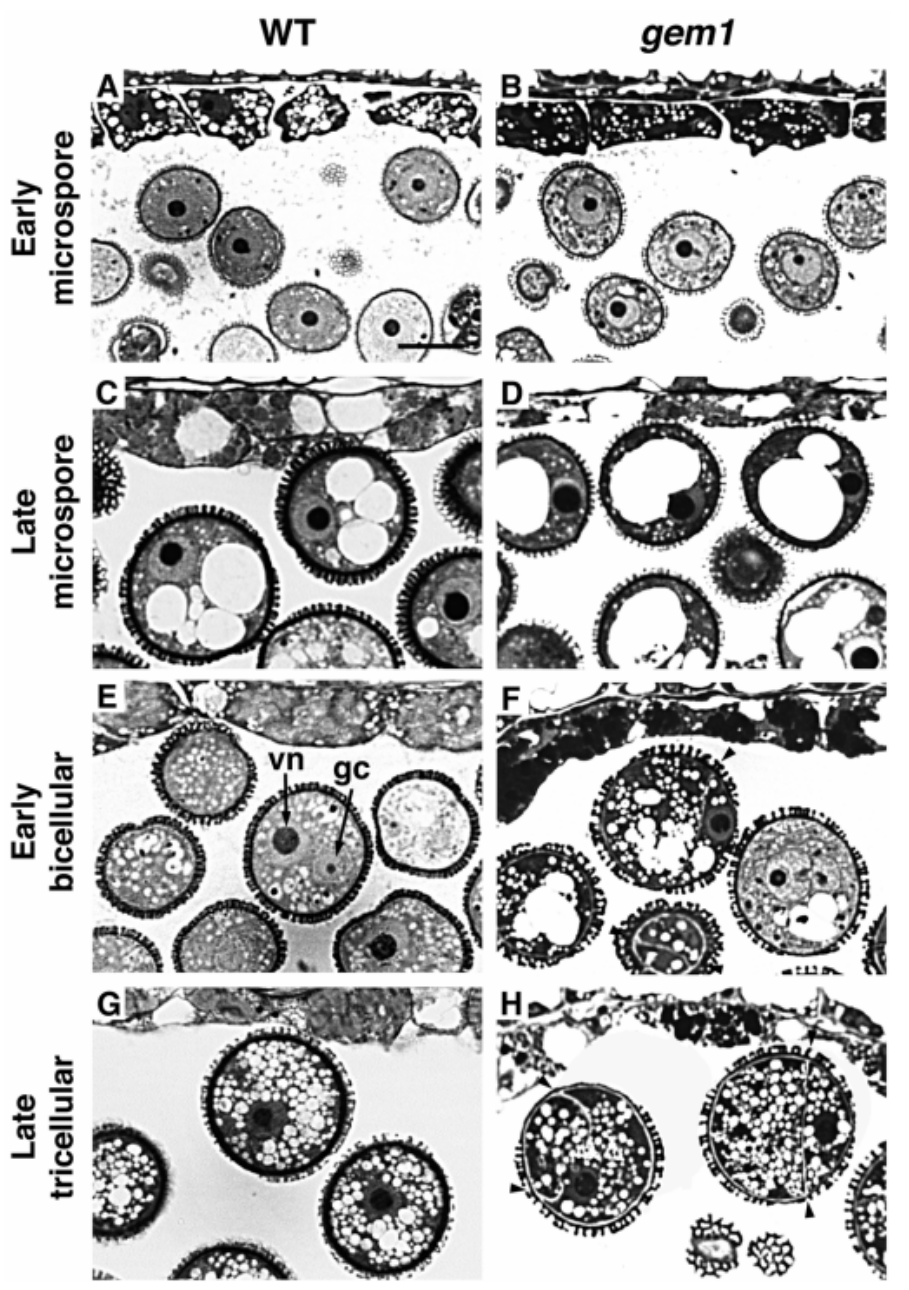

Fig. 4. Light micrographs of anther sections at different developmental stages in wild type (A,C,E,G) and geml (B,D,F,H). Early microspore with central nucleus $(\mathrm{A}, \mathrm{B})$; late microspore with polarized (acentric) nucleus (C,D); early bicellular (E,F) with vegetative nucleus (vn) and generative cell $(\mathrm{gc})$; late tricellular $(\mathrm{G}, \mathrm{H})$. Divided cells are not present at late microspore stage in $\mathrm{gem} 1$ (D). Partial and complete dividing walls in $\mathrm{gem} 1$ at early bicellular (F) and late tricellular stages $(\mathrm{H})$ are indicted by arrowheads. In geml $(\mathrm{H})$ well developed and curved internal wall profiles linked to the outer (pollen) wall are evident. Magnification is the same in all micrographs; scale bar (A) $10 \mu \mathrm{m}$.

\section{gem1 phenotypes result from aberrant cell divisions at PMI}

To analyze the earliest appearance and development of aberrant divisions in gem 1 pollen, spores at the tetrad through to mature pollen stages were analyzed by examining thick anther sections (Fig. 4). No evidence for premature partial or complete internal walls was observed in microspores at tetrad, early (Fig. 4A,B), mid or late (Fig. 4C,D) microspore stages before PMI. The earliest appearance of aberrant divisions was observed in anthers at PMI or early bicellular stages (Fig. 4E,F). Both complete and partial dividing walls were observed which persisted throughout pollen maturation (Fig. 4F,H). During later stages of pollen maturation these internal walls were more clearly defined indicating further elaboration during pollen maturation (Fig. 4G,H). 
Table 2. Tetrad analysis of $+/+; q r t 1 / q r t 1$ and $+/ g e m 1$; qrt1/qrt1 mutants

\begin{tabular}{|c|c|c|c|}
\hline \multirow[b]{2}{*}{ Phenotype } & \multicolumn{2}{|c|}{ Genotype } & \multirow{2}{*}{$\begin{array}{c}\text { Summary } \\
\% \text { tetrad classes in } \\
+/ \text { gem } 1 ; \text { qrt } 1 / \text { qrt } 1\end{array}$} \\
\hline & $\begin{array}{c}+/+; \text { qrt } 1 / q r t 1 \\
\text { No. of tetrads }(\%)\end{array}$ & $\begin{array}{l}\text { +/gem 1;qrt1/qrt1 } \\
\text { No. of tetrads }(\%)\end{array}$ & \\
\hline $\mathrm{wt} / \mathrm{wt} / \mathrm{wt} / \mathrm{wt}$ & 209 (99) & $53(20)$ & $4 \mathrm{wt}=20 \%$ \\
\hline wt / wt / wt / solo & - & $34(13)$ & \\
\hline wt / wt / wt / gem & - & $26(10)$ & $3 \mathrm{wt}$, \\
\hline wt / wt / wt / duo & $2(1)$ & $6(2)$ & 1 aberrant $=51 \%$ \\
\hline wt / wt / wt / abt & - & $69(26)$ & \\
\hline wt / wt / abt / solo & - & $13(5)$ & \\
\hline wt / wt / solo/ solo & - & $4(2)$ & \\
\hline $\mathrm{wt} / \mathrm{wt} / \mathrm{abt} / \mathrm{gem}$ & - & $19(7)$ & \\
\hline wt / wt / solo / gem & - & $6(2)$ & 2 aberrant $=29 \%$ \\
\hline $\mathrm{wt} / \mathrm{wt} / \mathrm{abt} / \mathrm{duo}$ & - & $3(1)$ & 2 aberrant $=29 \%$ \\
\hline wt / wt / gem / duo & - & $1(<1)$ & \\
\hline $\mathrm{wt} / \mathrm{wt} / \mathrm{abt} / \mathrm{abt}$ & - & $31(12)$ & \\
\hline Total & $211(100)$ & $265(100)$ & \\
\hline
\end{tabular}

The phenotypes of pollen grains present within mature tetrads were analyzed by light and epifluorescent microscopy after DAPI staining. Data was pooled from determinations on three individuals with the same genotype. abt, aborted pollen.

To provide a more detailed analysis of the ontogeny of the division phenotypes in geml, spores released from DAPIstained anthers at six distinct developmental stages were analyzed. At tetrad and early microspore stages the single nucleus was always centrally located in wild type (Fig. 5A) and geml (not shown). At the late microspore stage after cell expansion the wild type showed uniform microspore populations in which the nucleus was always clearly acentric and associated with the wall (Fig. 5B). However in geml at the equivalent stage $5-10 \%(n=239)$ of the microspore population were consistently observed with the nucleus in a central or intermediate position not closely associated with the wall (Fig. $5 \mathrm{G}, \mathrm{H})$. These apparently unpolarized microspores, which had expanded relative to the early microspore stage, suggest that aberrant divisions in geml may result from incomplete nuclear migration or fixation.

Detailed spore counts were carried out on anthers at three distinct stages of development after PMI, bicellular (Fig. 5D), tricellular (Fig. 5E) and mature pollen (Fig. 5F). Spore phenotypes were scored from individual anthers, since synchronicity was found to be very high within anthers, but not necessarily between anthers of the wild type. The most striking difference in development between wild type and geml was first apparent at the bicellular stage. gem 1 showed a similar frequency of aberrant pollen $(\sim 35 \%)$ at bicellular, tricellular and mature stages distributed among the same phenotypic classes (Fig. 6). However at the bicellular and tricellular stages, binucleate and divided bicellular pollen (Fig. 6A-E) comprised $\sim 90 \%$ of the aberrant pollen compared with $\sim 25 \%$ at the mature stage. The percentage of aberrant pollen with a single nucleus remained low $(\sim 6-8 \%)$ in the bicellular and tricellular stages, but showed a marked increase to approximately $63 \%$ in mature pollen (Fig. 6F-H). These data confirm that aberrant divisions in geml occur as a result of failed or aberrant cytokinesis at PMI, and strongly suggest that the frequent solo (Fig. 1B) and uninucleate divided (Fig. $6 \mathrm{G})$ phenotypes in mature pollen result from nuclear fusion very late during pollen maturation or upon rehydration.

\section{Aberrant divisions are aligned with the polar axis in gem1}

The plane of division in pollen of geml was determined relative to the polar axis. The polar axis of the microspore is defined by the proximal-distal axis of the microspore in the tetrad (Erdtman, 1952). In species in which the microspores are held together in permanent tetrads it has been possible to determine the polarity of nuclear migration. The direction of nuclear migration can be either along the polar axis towards the inner (proximal) or outer (distal) walls of the tetrad, or perpendicular to the polar axis, towards a radial wall, depending upon the species (Geitler, 1935; Maheshwari, 1950). In Arabidopsis microspores, the polar axis is aligned with the long axis of the three germination pores in the radial walls (Fig. 7A,H). When viewed through the polar axis the three apertures are apparent as regions of local exine thinning equally spaced around the pollen wall (Fig. 7A-D). However, when viewed through a radial wall at the equator the apertures are not visible (Fig. 7I-K).

The polarity of nuclear migration and division plane has not previously been defined in Arabidopsis. Therefore, the site of division was determined in the wild type by examining spores released from anthers at PMI when the GC was still attached to the pollen wall. At this stage the GC is surrounded by a prominent domed wall visible by light microscopy (Fig. 7EG). In approximately $90 \%$ of spores viewed through a radial

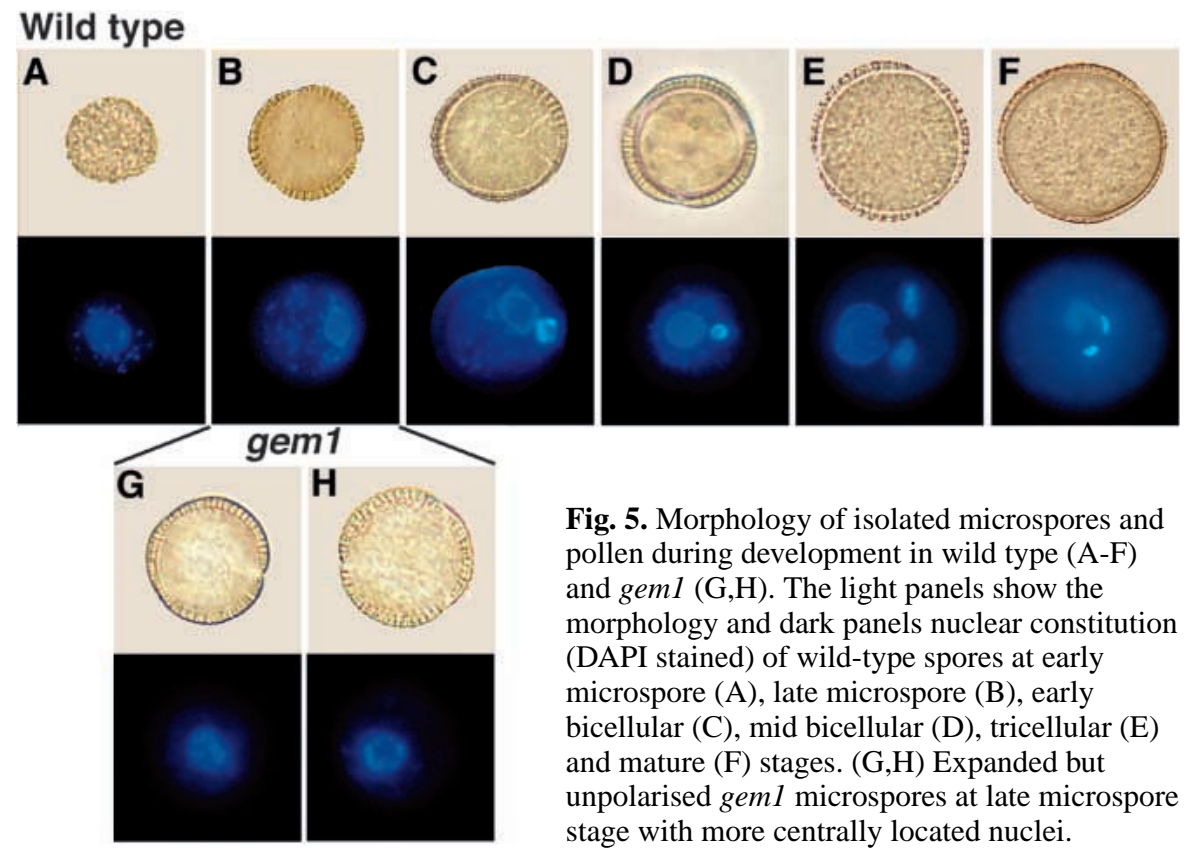




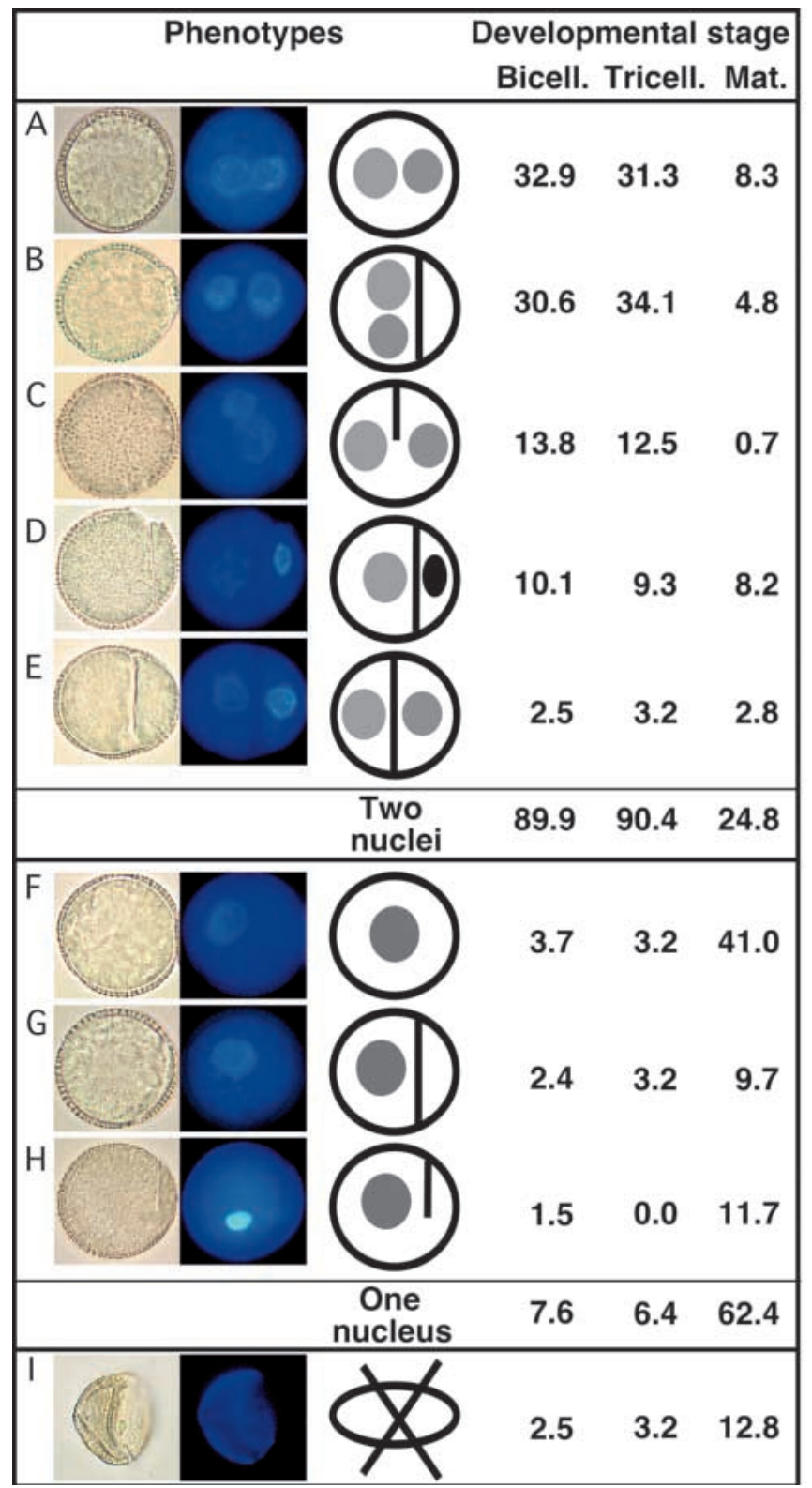

Fig. 6. Frequency of aberrant phenotypes during pollen development in geml. (A-I) Light and DAPI fluorescence micrographs of aberrant pollen classes at the late tricellular stage, except $(\mathrm{H})$, which is from the mature stage. The frequencies of each phenotypic class, calculated as a percentage of the total aberrant pollen, at bicellular (bicell.), tricellular (tricell.) and mature (mat.) pollen stages are shown. The sums of spore classes with one or two nuclei are shown. More than 400 spores were counted at each stage.

wall the GC appeared to be attached at radial wall at the equator (Fig. $7 \mathrm{~L}, \mathrm{M}$ ) and in $\sim 10 \%$ of spores at a position along a radial wall intermediate between the equator and a pole (Fig. $7 \mathrm{~N}, \mathrm{O}$ ). The $\mathrm{GC}$ was never observed in a polar position (Fig. $7 \mathrm{~K})$. Therefore the plane of division at PMI in Arabidopsis is normally parallel and sometimes oblique to the polar axis. However, there was no clear relationship between the division site and the apertures. The GC was most often associated with or overlying the apertures (Fig. 7B,D,E,G), but divisions also

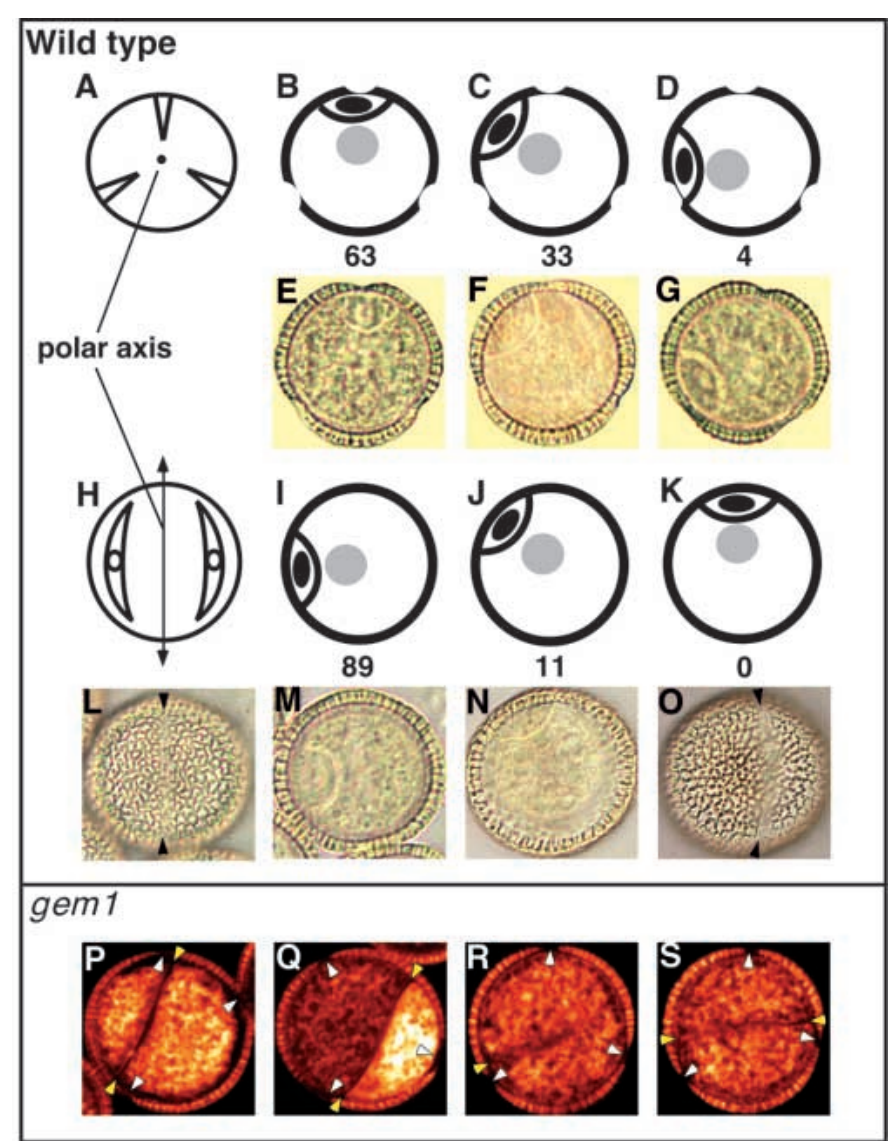

Fig. 7. Division axis at PMI in wild type (A-O) and geml (P-S). The proximal-distal axis of spores in the tetrad defines the polar axis, which in Arabidopsis is parallel to the long axis of the three apertures in the radial walls. The potential division sites in spores viewed through the proximal/distal pole (A-D) or through a radial wall $(\mathrm{H}-$ $\mathrm{K})$ are shown. The frequency (\%) of wild-type spores with the $\mathrm{GC}$ at different positions when observed in polar or radial view are shown (polar view E-G; radial view L-O). L and $\mathrm{O}$ are surface views of spores $\mathrm{M}$ and $\mathrm{N}$ showing aperture orientation (black arrowheads). $(\mathrm{P}, \mathrm{Q})$ Optical CLSM sections of two gem 1 pollen grains with the division plane parallel to the polar axis. $(\mathrm{R}, \mathrm{S})$ Two serial optical sections through a divided geml pollen grain showing a shift in wall position between sections. White and yellow arrowheads indicate the sites of apertures and the division plane respectively.

frequently positioned the GC between two apertures (Fig. 7C,F).

In gem 1 pollen images of a randomly selected population of twin-celled pollen in mature anthers, irrespective of nuclear condition, were captured and their division planes scored relative to the polar axis using aperture positions as markers. In completely divided cells three apertures were nearly always $(95 \% ; n=36)$ visible strongly suggesting that the plane of division was aligned with or tangential relative to the polar axis (Fig. 7P,Q). Dividing walls, which were only rarely observed in spores viewed through a radial wall at the equator, were also roughly aligned with the polar axis (not shown). Incomplete walls frequently changed position upon refocussing suggesting curved and irregular profiles, which was confirmed by optical sectioning using confocal laser scanning microscopy (CLSM; Fig. 7R,S). 
Fig. 8. Pollen phenotypes in mature tetrads of + + ; qrt1/qrtl (A) and +/gem1; qrt1/qrtl (B-F) plants. Corresponding DAPI-stained tetrads are shown below light micrographs A-C. (A) All four tetrad members show two bright sperm nuclei and a diffuse vegetative nucleus. (B) +/gem 1; qrt1/qrt1 tetrad showing two wildtype spores and two aborted spores with no nuclei. (C) +/geml; qrt1/qrtl tetrad showing one unequally divided spore with more intense DAPI staining in the nucleus of the smaller cell. (D,E) Further examples of divided spores with the plane of division orientated along the polar axis. (F) Left to right: four serial optical sections through a +/gem 1; qrtl/qrtl tetrad stained with EtBr showing one divided member. The uppermost member of the tetrad (left) is viewed through the polar axis with positions of the apertures indicated by white arrowheads. The two lower sections (right) show one divided member in which the position of the division (yellow arrowheads) shifts between sections.
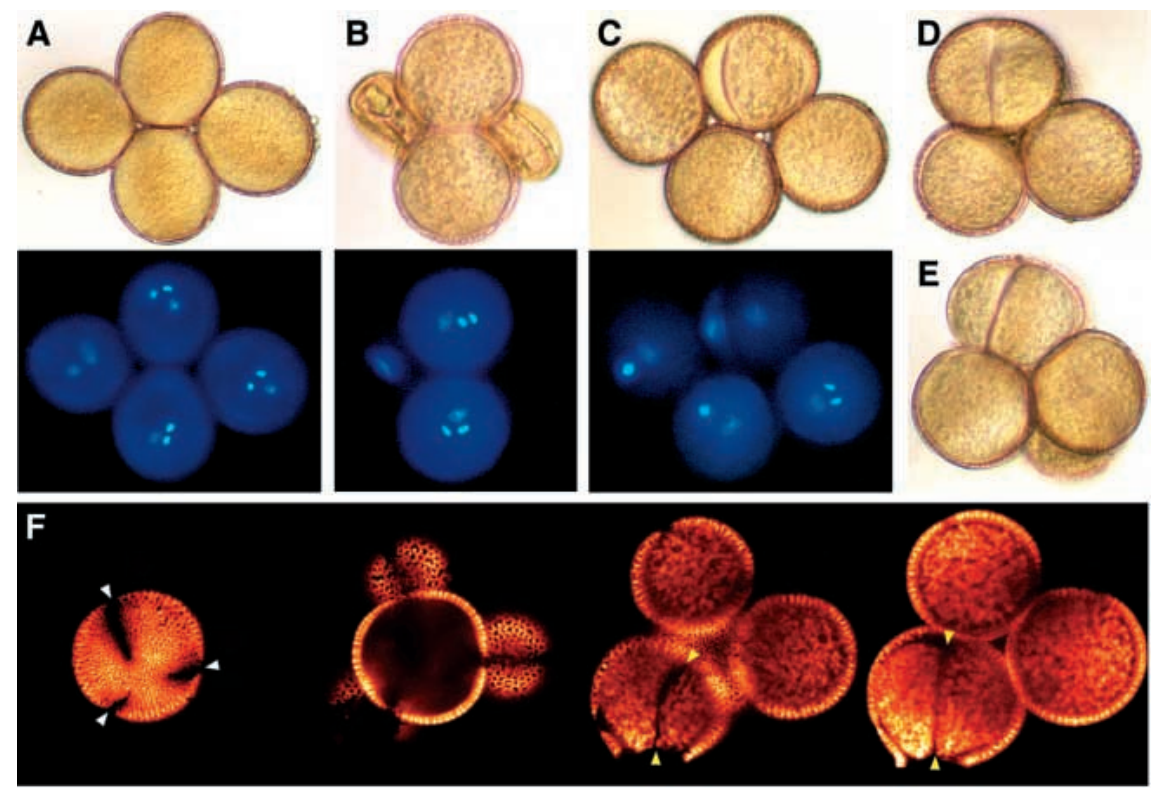

The division axis in geml was further analyzed in +/gem 1;qrt1/qrtl double mutants. The meiotically determined tetrahedral arrangement of microspores is maintained in qrt 1 with their polar axes passing through the centre of the tetrad (Fig. 8A; Preuss et al., 1994). Therefore the longitudinal axis of the apertures was used to determine the division plane in divided pollen within tetrads. In all tetrads examined $(n=64)$ dividing walls were either aligned with (Fig. 8C,D) or tangential (Fig. 8E) to the polar axis. Confirmation of the division plane roughly parallel to the polar axis was obtained by optically sectioning divided pollen within tetrads by CLSM (Fig. 8F).

\section{Cell fate analysis in gem1 pollen}

In completely divided, twin-celled pollen, division asymmetry was observed across the entire range from highly asymmetric to nearly equal divisions. This range was exploited to investigate the relationship between division symmetry and cell fate using condensed nuclear chromatin as a GC fate marker, and expression of the VC-specific transgene, lat52-gus/nia (Twell, 1992) and dispersed chromatin as VC fate markers. The VC fate marker was introduced into geml by outcrossing with a transgenic plant homozygous for lat52-gus/nia (for details see Materials and Methods).

Solo pollen stained positive with X-gluc and showed a dispersed DAPI-stained nucleus, both characteristics of VC fate (Fig. 9B). Similarly, in symmetrically divided cells, both expressed GUS activity and showed dispersed nuclear chromatin (Fig. 9E). However, a novel finding was that in asymmetrically divided cells the smaller daughter cell showed characteristics of both vegetative and generative cell fate. The smaller daughter cell always stained less intensely with X-gluc than its larger sister cell while the reverse relationship was observed for the intensity of DAPI staining (Fig. 9C, D). Even in highly asymmetric divisions lat52 was still expressed at low levels in the smaller daughter cell which also showed more condensed nuclear chromatin (Fig. 9C). Therefore in unequal divisions that were less asymmetric than wild type the smaller daughter cell always possessed an intermediate or mixed cell fate. However, even in binucleate cells in which both nuclei were generally dispersed, some degree of chromatin heteronomy was maintained within the common cytoplasm (Fig. 6A-C).

\section{DISCUSSION}

Direct phenotypic screening of an EMS mutagenized Arabidopsis population led to the isolation of four independent mutants producing mature pollen in a divided or twin-celled condition. The geml mutant, which showed the most severe
A
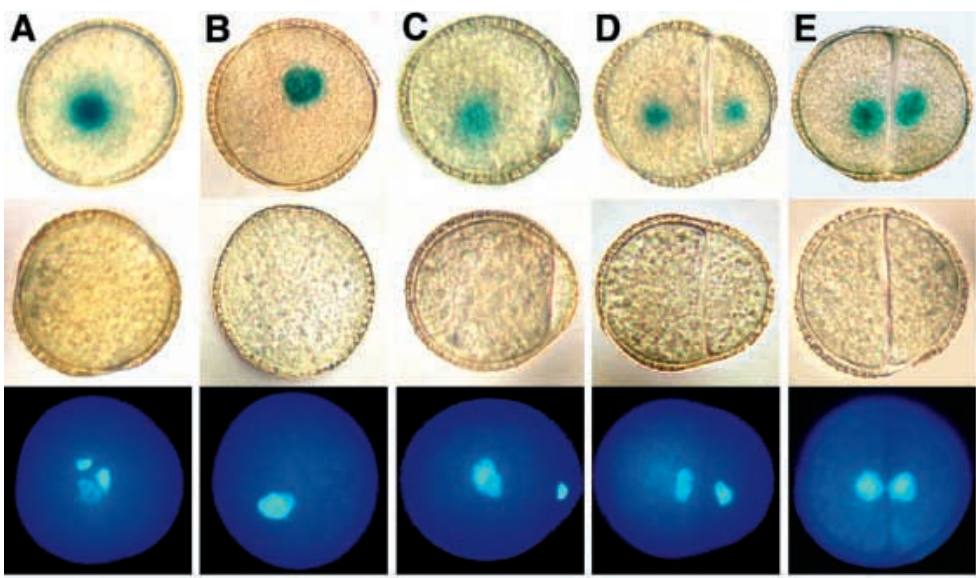

Fig. 9. Cell fate analysis in wild type (A) and a range of geml spores with different division phenotypes (B-E). (B) Solo pollen. (C) Highly unequal division, (D) unequal division, (E) equal division. Top row, spores expressing the lat52-gus/nia vegetative cell fate marker after incubation with X-gluc. Middle and bottom rows, light and corresponding DAPI fluorescence images of spores with similar phenotypes to those shown in the top row. 
phenotype, was analyzed in detail as a type member of this mutant class.

\section{gem1 is an incompletely penetrant gametophytic mutation}

Genetic transmission and tetrad analysis define geml as an incompletely penetrant gametophytic mutation with only $40 \%$ of the pollen population showing an aberrant phenotype in homozygotes. Therefore $60 \%$ of pollen carrying the geml mutant allele have a wild-type appearance and would be expected to successfully fertilize an ovule. In fact only $18.6 \%$ of pollen carrying geml was successful in the heterozygote, suggesting that $\mathrm{gem} l \mathrm{can}$ reduce pollen fertility independently of any visible defect. Therefore, in addition to the role of GEMI in asymmetric division GEMI is likely to have an important role in later events during maturation or the progamic phase. The low female transmission $(\mathrm{TE}=29.5 \%)$ further shows that GEMI action is not restricted to the male gametophyte and may act during megagametophyte development and/or function. It will be interesting to determine whether the characteristic nuclear migration and/or cellularization are also affected during megagametophyte development in geml. In this regard several femalegametophyte-specific mutants have been identified in Arabidopsis (Drews et al., 1998) including the hadad mutant, which affects nuclear migration (Moore et al., 1997).

\section{gem1 affects cytokinesis but not karyokinesis at PMI}

The major visible and earliest phenotypes resulting from the gem 1 mutation were first apparent at PMI with aberrant, partial or failed cytokinesis. The frequent occurrence of binucleate spores immediately after PMI shows that geml does not prevent entry into mitosis and completion of karyokinesis. Developmental analysis showed that binucleate undivided spores persisted until the late tricellular stages but were replaced by uninucleate solo pollen in shed pollen, strongly suggesting nuclear fusion at the final stages of maturation or during pollen dehydration/rehydration. Furthermore, the increased nuclear DAPI staining in solo pollen is consistent with increased DNA content as a result of nuclear fusion. The presence of two active nuclei before fusion could be responsible for the increased size of solo pollen, since diploid pollen of tetraploid parents is larger than haploid pollen, presumably as a result of the activity of two haploid genomes (Altman et al., 1994). Nuclear fusion has been reported in tetranucleate spores of the Arabidopsis tetraspore mutant, but here fusion events appear to occur before PMI and during pollen maturation (Spielman et al., 1997).

The complex division phenotypes suggest that GEMI is required for the coordination of karyokinesis and cytokinesis at PMI. Common geml phenotypes showed spatial uncoupling of karyokinesis and cytokinesis resulting in binucleate cells with enucleate cytoplasmic partitions. It is unlikely that cytokinesis fails in geml simply because the wall synthesizing enzymes are defective since geml pollen is frequently able to synthesize well developed internal walls. However it is possible that the intracellular targeting machinery required for cell plate synthesis is defective in geml. For example ectopic phragmoplast activity in gem 1 outside the mitotic spindle could lead to partial walls and frequent uncoupling of nuclear division and cytokinesis. geml shows that although karyokinesis and cytokinesis are normally closely coupled at PMI these processes can operate independently. This concept has been elegantly demonstrated in experiments in which chromosomes were physically removed from the mitotic spindle in insect cells. Chromosomeless cells still executed normal cytokinesis to produce enucleate daughters (Zhang and Nicklas, 1996). GEMI could therefore play a role in the spatial coordination of karyokinesis and cytokinesis and may be of particular value in understanding how these processes are normally controlled during asymmetric cell division.

Other Arabidopsis mutants which alter the position and synthesis of the cell plate but act sporophytically in the early embryo and developing seedling include the gnom and knolle mutants (Mayer et al., 1993; Lukowitz et al., 1996). knolle in particular shows cells with partial walls and multi-nucleate cells which appear to result from incomplete cytokinesis. The GNOM protein shows sequence similarity to the yeast Sec7 domain which is involved in protein transport through the golgi (Shevell et al., 1994), while KNOLLE is similar to T-SNARE proteins (syntaxins) which are involved in vesicle docking (Lukowitz et al., 1996). KNOLLE was localized to the developing phragmoplast and is therefore a cytokinesisspecific syntaxin, but was absent from the specialized phragmoplasts formed during telophase II of male meiosis (Lauber et al., 1997). If similar proteins function in the asymmetric positioning and synthesis of the cell plate at PMI it is possible that GEM1 encodes a related gametophytespecific protein.

\section{The role of microspore polarity in Arabidopsis}

In species that shed pollen in permanent tetrads it has been possible to determine the polarity of nuclear migration. Although the position of the GC at PMI in relation to the organization of the tetrad differs between species, nuclear migration is regular within species and appears to be predetermined towards a fixed location (Geitler, 1935). Here we showed that in Arabidopsis microspore nuclear migration is towards a radial wall of the spore, but never at the poles. This is consistent with either an asymmetric gradient of a polarity determinant between the radial walls, or a radiating gradient which does not operate at the poles (Twell et al., 1998). We propose that the role of the microspore polarity system in Arabidopsis is twofold; first, to ensure nuclear migration to an equatorial wall and second, to ensure that the correct spindle axis is established to achieve asymmetric division. In geml only the first component appears to be affected since the division plane was predominantly aligned with the polar axis as in the wild type.

\section{gem1 disturbs microspore polarity}

The symmetric and asymmetric division phenotypes in gem 1 show that the expression of polarity is disturbed. Aberrant divisions occurred at the correct time, therefore geml microspores do not appear to enter a heterochronic or premature division. In contrast, in the $s c p$ mutant, microspores undergo a premature equal division and only one daughter cell retains the ability to divide asymmetrically. $s c p$ supports models of polarity determination by asymmetrically localized factors (Chen and McCormick, 1996; Twell et al., 1998). According to one such model the premature symmetric 
division in $s c p$ would lead to the differential inheritance of a localized polarity determinant (Chen and McCormick, 1996). In gem 1, neither daughter cell retains the ability to express polarity and achieve asymmetric division. In contrast to $s c p$, which may act as a repressor of cell division (Chen and McCormick, 1996), the geml phenotype is consistent with the loss of a polarity determinant in geml or of factors required for polarity expression.

\section{Cell fate determination is quantitatively dependent on division asymmetry}

Two general models, the active and passive repression models, have been proposed to account for how VC-specific genes are normally repressed in the $\mathrm{GC}$ as a result of asymmetric division (Eady et al., 1995), both involving the polarised distribution of gametophytic regulatory factor(s). The results of cell fate analysis in geml are consistent with the predictions of both models but also provide further insight into the nature of cell fate determination. First, the expression of the lat52 marker and dispersed nuclear chromatin in solo and binucleate pollen showed that division at PMI is not required for expression of VC-fate in Arabidopsis. This confirms VC fate as the default condition in the absence of division at PMI. Second, in symmetrically divided gem 1 microspores both daughter cells activated the VC marker and showed more dispersed nuclear chromatin, confirming that division asymmetry is required for GC differentiation (Eady et al., 1995). However, in asymmetrically divided cells the smaller daughter cell shared intermediate characteristics of both vegetative and generative cell fate. Furthermore, smaller daughter cells did not undergo inward migration and engulfment or divide to form two sperms cells. This may also be a consequence of their mixed cell fate, since inward migration and continued mitosis are GC characteristics. Cell fate determination therefore appears to be a quantitative phenomenon, dependent on cell size (or the degree of division asymmetry) at PMI.

With regard to the active and passive repression models, intermediate cell fate in geml could be caused by disturbed partitioning of the hypothetical cell gametophytic factor (GF) and/or generative cell repressor (GCR; Twell et al., 1998) and/or by the modification of their activities in a quantitatively different cytoplasmic environment. The identification of GCspecific histone variants and the observed VC-specific decline in histone H1 levels in Lilium (Ueda and Tanaka, 1995) provide a potential mechanism to establish and maintain chromatin heteronomy following PMI (Twell et al., 1998). In this regard binucleate, undivided geml pollen showed chromatin heteronomy with one highly dispersed 'vegetative like' nucleus and one smaller more intensely staining, but relatively dispersed nucleus. The maintenance of chromatin heteronomy in the same cytoplasm suggests that the generative pole nucleus may specifically retain factors which limit chromatin dispersion following mitosis. Since chromatin heteronomy is apparent during late anaphase to early telophase (Terasaka and Tanaka, 1974) such factors could become chromatin associated either before or during mitosis. These observations are consistent with a modified active repression model in which the polarised distribution of GCRs determines GC chromatin dispersion and repression of VC-specific genes (Twell et al., 1998). Furthermore, if the polarized transport of a GCR was determined by the same system as that controlling nuclear migration this could provide a link between polarity and cell fate determination. The mutant phenotypes observed are consistent with this hypothesis since both are disturbed in geml.

In summary, GEMI defines a unique gametophytically expressed factor required for correct nuclear migration and the spatial coordination of karyokinesis and cytokinesis at PMI. GEMI therefore represents a component of the pathway which signals and executes microspore polarity and asymmetric division. Further detailed phenotypic analysis and the cloning of $G E M 1$ is now underway to elucidate the precise function of GEM1 in this pathway.

We gratefully acknowledge The Royal Society, The Korea Research Foundation and BBSRC under the Cell Commitment and Determination Initiative for financial support. We also thank Igor Vizir for valuable advice and analysis of mapping data, Carol Wilson and Simson Leigh for assistance with transmission analysis and mutant screening, Evaline Roberts for advice on thick sectioning, Andy Hubberd at the MRC Centre for Mechanisms of Human Toxicity for confocal microscopy and June Saddington and Graham Benskin for maintaining mutant populations. qrtl seed was obtained from the Nottingham Arabidopsis Stock Centre.

\section{REFERENCES}

Altmann, T., Damm, B., Frommer, W. B., Martin, T., Morris, P. C., Schweizer, D., Wilmitzer, L., Schmidt, R. (1994). Easy determination of ploidy level in Arabidopsis thaliana plants by means of pollen size measurement. Plant Cell Rep. 13, 652 - 656.

Bell, C.J. and Ecker, J.R. (1994). Assignment of 30 microsatellite loci to the linkage map of Arabidopsis. Genomics 19, 137-144.

Brown, R.C. and Lemmon, B.E. (1991). Pollen development in orchids. 3. A novel generative pole microtubule system predicts unequal pollen mitosis. J. Cell Sci. 99, 273-281.

Brown, R.C. and Lemmon, B.E. (1992). Pollen development in orchids. 4. Cytoskeleton and ultrastructure of the unequal pollen mitosis in Phalaenopsis. Protoplasma 167, 183-192.

Chen, Y-C. and McCormick, S. (1996). sidecar pollen, an Arabidopsis thaliana male gametophytic mutant with aberrant cell divisions during pollen development. Development 122, 3243-3253.

Drews, G.N., Lee, D. and Christensen, C.A. (1998). Genetic analysis of female gametophyte development and function, Plant Cell 10, 5-18.

Eady, C., Lindsey, K. and Twell, D. (1994). Differential activation and conserved vegetative-cell-specific activity of a late pollen promoter in species with bi- and tricellular pollen. Plant J. 5, 543-550.

Eady, C., Lindsey, K and Twell, D. (1995). The significance of microspore division and division symmetry for vegetative cell-specific transcription and generative cell differentiation. Plant Cell 7, 65-74.

Edwards, K., Johnstone, C. and Thompson, C. (1991). A simple and rapid method for the preparation of plant genomic DNA for PCR analysis. Nucl. Acids Res. 19, 1349.

Erdtman, G. (1952) Pollen Morphology and Plant Taxonomy - Angiosperms (An Introduction to Palynology. I), Almqvist and Wiksell.

Geitler, L. (1935). Beobachtungen über die erste Teilung im Pollenkorn der Angiospermen. Planta 24, 361-386.

Gervais, C., Simmonds, D.H. and Newcomb, W. (1994). Actin microfilament organization during pollen development of Brassica napus cv. Topas. Protoplasma 183, 67-76.

Hause, G., Hause, B. and van Lammeren, A.A.M. (1991). Microtubular and actin-filament configurations during microspore and pollen development in Brassica napus L. cv. Topas. Can. J. Bot. 70, 1369-1376.

Horvitz, R.H. and Herskowitz, I. (1992). Mechanisms of asymmetric cell division: Two Bs or not two Bs, that is the question. Cell 68, 237-255.

Howden, R., Park, S. K., Moore, J.M., Orme, J., Grossniklaus, U and Twell, D. (1998). Selection of T-DNA-tagged male and female gametophytic mutants by segregation distortion in Arabidopsis. Genetics (in press). 
Jan, Y.N. and Jan, L.Y. (1998). Asymmetric cell division. Nature 392, 775 778.

Koornneef, M. and Stam, P. (1992). Genetic analysis, in Methods in Arabidopsis Research (ed. Konz, C., Chua, N.-H. and Schell, J.), pp. 83-99. Singapore: World Scientific.

Lauber, M.H., Waizenegger, I., Steinmann, T., Schwarz, H., Mayer, U., Hwang, I., Lukowitz, W. and Jurgens, G. (1997). The Arabidopsis KNOLLE protein is a cytokinesis-specific syntaxin. J. Cell Biol. 139, 1485-1493.

LaCour, L.F. (1949). Nuclear differentiation in the pollen grain. Heredity 3 , 319-338.

Lukowitz, W., Mayer, U. and Jurgens, G. (1996). Cytokinesis in the Arabidopsis embryo involves the syntaxin-related KNOLLE gene product. Cell 84, 61-71.

Maheshwari, P. (1950). An Introduction to the Embryology of the Angiosperms. McGraw-Hill.

Mayer, U., Buttner, G. and Jürgens, G. (1993). Apical-basal pattern formation in the Arabidopsis embryo: studies on the role of the gnom gene. Development 117, 149-162.

Moore, J. M., Vielle-Calzada, J.-P., Gagliano, W. and Grossniklaus, U. (1997). Genetic characterization of hadad, a mutant disrupting female gametogenesis in Arabidopsis thaliana. Cold Spring Harbor Symp. Quant. Biol. 62, 35-47.

Owen, H.A. and Makaroff, C.A. (1995). Ultrastructure of microsporogenesis and microgametogenesis in Arabidopsis thaliana (L.) Heynh. ecotype Wassilewskija (Brassicaceae). Protoplasma 185, 7-21.

Preuss, D., Rhee, S.Y. and Davis, R.W. (1994) Tetrad analysis possible in Arabidopsis with mutation of the QUARTET (QRT) genes. Science 264, 1458-1460.

Sari-Gorla, M., Ferrario, S., Villa, M., Pe, M.E. (1996). gaMS-1 a gametophytic male-sterile mutant in maize. Sex. Plant Reprod. 9, 216-220.

Shevell, D.E., Leu, W-M., Gilimor, C.S. Xia, G., Feldmann, K.A. and Chua, N-H. (1994). EMB30 is essential for normal cell division, cell expansion, and cell adhesion in Arabidopsis and encodes a protein that has similarity to Sec7. Cell 77, 1051-1062.

Spielman, M.L., Preuss, D., Li, F-L., Browne, W.E., Scott, R. and Dickinson, H.G. (1997). TETRASPORE is required for male meiotic cytokinesis in Arabidopsis thaliana. Development 124, 2645-2657.
Tanaka, I. (1997). Differentiation of generative and vegetative cells in angiosperm pollen. Sex Plant Reprod 10, 1-7.

Tanaka, I., and Ito, M. (1981). Control of division patterns in explanted microspores of Tulipa gesneriana. Protoplasma 108, 329-340.

Terasaka, O. and Tanaka, R. (1974). Cytological studies on the nuclear differentiation in microspore division of some angiosperms. Bot. Mag. Tokyo 87, 209-217.

Terasaka, O. and Niitsu, T. (1990). Unequal cell division and chromatin differentiation in pollen grain cells. II. Microtubule dynamics associated with the unequal cell division. Bot. Mag. Tokyo 103, 133-142.

Twell, D. (1992). Use of a nuclear-targeted $\beta$-glucuronidase fusion protein to demonstrate vegetative cell-specific gene expression in developing pollen. Plant J. 2, 887-892.

Twell, D. (1994). The diversity and regulation of gene expression in the pathway of male gametophyte development, in Molecular and Cellular Aspects of Plant Reproduction, (ed. Scott, R.J and Stead, A.D.), pp. 83-135, Cambridge: Cambridge University Press.

Twell, D. and Howden, R. (1998) Mechanisms of asymmetric division and cell fate determination in developing pollen In Androgenesis and Haploid Plants, 1967-1994. In memory of Jean-Pierre Bourgin. (ed. Chupeau, Y., Caboche, M., Henry, Y.), pp. 68-103. INRA-Springer-Verlag.

Twell, D., Yamaguchi, J., and McCormick, S. (1990). Pollen-specific gene expression in transgenic plants: Coordinate regulation of two different tomato gene promoters during microsporogenesis. Development 109, 705713.

Twell, D., Patel, S., Sorensen, A., Roberts, M., Scott, R., Draper, J. and Foster, G. (1993). Activation and developmental regulation of an Arabidopsis anther-specific promoter in microspores and pollen of Nicotiana tabacum. Sex. Plant Reprod. 6, 217-224.

Twell, D., Park, S.K. and Lalanne, E. (1998). Asymmetric division and cell fate determination in developing pollen. Trends Pl. Sci. (in press)

Ueda, K. and Tanaka, I. (1995). The appearance of male gamete-specific histones gH2B and $\mathrm{gH} 3$ during pollen development in Lilium longiflorum. Dev. Biol. 169, 210-217.

Zhang, D. and Nicklas, R.B. (1996). 'Anaphase' and cytokinesis in the absence of chromosomes. Nature 382, 466-468. 